\title{
Preliminarily phytochemical screening and in vivo safety evaluation of ethanolic extract of Hemidesmus indicus (Linn.)
}

\author{
Gita Mishra $^{1}$, Hemeshwer Kumar Chandra ${ }^{1}$, Nisha Sahu ${ }^{1}$, Satendra Kumar Nirala ${ }^{2}$, Monika Bhadauria $^{1 *}$ \\ ${ }^{1}$ Department of Zoology, Toxicology and Pharmacology Laboratory, Guru Ghasidas University, Bilaspur, Chhattisgarh, India. \\ ${ }^{2}$ Department of Rural Technology and Social Development, Laboratory of Natural Products, Guru Ghasidas University, Bilaspur, Chhattisgarh, India.
}

\begin{tabular}{l}
\hline ARTICLE INFO \\
\hline Received on: $28 / 05 / 2018$ \\
Accepted on: $12 / 10 / 2018$ \\
Available online: $30 / 12 / 2018$ \\
\\
\hline Key words: \\
Hemidesmus indicus, \\
phytochemical analysis, \\
NOAEL, choleretic activity.
\end{tabular}

\section{INTRODUCTION}

Plants have been a source of many important medicaments since ancient time for indigenous people (Fabricant and Farnsworth, 2001). A significant proportion of the population (approx. 80\%) in developing countries still depends on the traditional remedies to treat several diseases (Pal and Shukla, 2003). Hemidesmus indicus (Linn.) of Apocynaceae (subfamily Asclepiadaceae) is known as Indian sarsaparilla in English, Anantmul in Hindi, and Ananta in Sanskrit language. It is well distributed throughout India and frequently used in Indian traditional medicine (Nair et al., 2014). It is a thick,

"Corresponding Author

Monika Bhadauria, Associate Professor, Department of Zoology,

Toxicology and Pharmacology Laboratory, Guru Ghasidas University,

Bilaspur,Chhattisgarh,_India.E-mail: bhadauria_monika@,rediffmail.com woody plant with brown and fragment bark. It is popularly used for the treatment of blood diseases, dyspnea, dyspepsia, loss of flavor, dyspnea, cough, menstrual problems, fever, diarrhea (Mary et al., 2003), and cancer (Ferruzzi et al., 2013; Fimognari et al., 2011; Samarakoon et al., 2012; Zarei and Javarappa, 2012). Hemidesmus indicus has a potential hepato-protective, nephronprotective, and anti-inflammatory activity (Kotnis et al., 2004; Qureshi et al., 1997).

Safety of plant-based medicines has frequently been questioned due to reported toxic effects in test animals (Park et al., 2010). Safety evaluation is important for hazard identification and standardization of novel drugs. Regulatory safety assessment for herbal products relies on a range of adverse drug reactions and published toxicity reports (De Smet, 1995). The choleretic agent is a drug which stimulates bile flow and increases solid contents in bile. Choleretic effects of the herbal medicine and its component have been a good source of scientific information for their 
clinical use in wide variety of liver diseases (Hoefler et al., 1987; Wang et al., 2016).

Hemidesmus indicus may represent an interesting botanical drug (Turrini et al., 2015), however, scientific basis for its safety has not been reported. Thus, the aim of this investigation was a qualitative and quantitative analysis of $H$. indicus leaf, stem, and root extract followed by safety evaluation of the root extract. Since $H$. indicus possesses potent hepatoprotective activity, the present investigation will also explore its therapeutic effect relating to its choleretic activity in rats.

\section{MATERIALS AND METHODS}

\section{Collection and extraction}

The whole plant was collected from Bilaspur district, Chhattisgarh in India. The plant was identified by an eminent botanist, and voucher specimen No. GG/C/APO/101 was deposited in the herbarium of Department of Botany, Guru Ghasidas University. Fresh leaves, stems, and roots were separated from the plant and washed in distilled water to remove dust. Then it was dried in shade at room temperature. Dried plant parts were subsequently sieved separately to obtain a fine powder. Then $70 \%$ hydroethanolic extracts of the fine powder was prepared using an accelerated solvent extractor (DIONEX. ASE-150) at $20^{\circ} \mathrm{C}$ and 15 atm pressure (Azwanida, 2015). Standardized modern analytical methods were used to ensure quality control of plant extract (Fibigr et al., 2018). The extracts were dried at room temperature and their residues were weighed and recorded. The yield of leaves, stem, and root of $H$. indicus extracts was found to be $16.7 \% \mathrm{w} / \mathrm{w}$, $19.2 \% \mathrm{w} / \mathrm{w}$, and $20.7 \% \mathrm{w} / \mathrm{w}$, respectively. The extracts were dried at room temperature and stored in a refrigerator at $4{ }^{\circ} \mathrm{C}$ for their future use in phytochemical and toxicity analysis.

\section{Qualitative phytochemical analyses}

A small portion of $H$. indicus ethanolic extract was used for qualitative phytochemical screening of alkaloids, flavonoids, tannins, saponins, terpenoids, carbohydrate, glycosides, and proteins according to standardized protocols given by Harbone (1973) and Trease and Evans (1989).

\section{Quantitative phytochemical analyses}

\section{Determination of hydrogen peroxide $\left(\mathrm{H}_{2} \mathrm{O}_{2}\right)$ scavenging activity}

Determination of $\mathrm{H}_{2} \mathrm{O}_{2}$ scavenging activity was done by the method of Ruch et al. (1989). Absorbance was recorded in UV/VIS spectrophotometer at $230 \mathrm{~nm}$. A standard curve prepared using a different concentration of ascorbic acid. The results were expressed as $\mathrm{H}_{2} \mathrm{O}_{2}$ scavenging activity/ $\mu \mathrm{g}$ of extract.

\section{Determination of total polyphenolic content}

The polyphenolic content was determined by the FolinCiocalteu assay of Slinkard and Singleton (1997). Absorbance of the test sample was recorded at $725 \mathrm{~nm}$. Total polyphenolic content was determined by plotting a standard curve using different concentrations of gallic acid. The results were expressed in $\mathrm{mg} / \mathrm{g}$ of extract.

\section{Determination of flavone and flavonol content}

Total flavone and flavonol content were determined by the aluminium chloride method of Cvek et al. (2007). Absorbance was measured at $415 \mathrm{~nm}$. The total polyphenol content was determined by plotting a standard curve using different concentrations of quercetin. The results were expressed in $\mathrm{mg} / \mathrm{g}$ of extract.

\section{Determination of flavonones}

The flavonone content was determined by using the 2,4-Dinitrophenylhydrazine method of method of Cvek et al. (2007). Absorbance was measured at $495 \mathrm{~nm}$. The flavonone content was determined by plotting a standard curve using different concentrations of pinostrobin. The flavonone content was expressed in $\mathrm{mg} / \mathrm{g}$ of extract.

\section{Determination of flavonoid content}

Total flavonoid was determined by measuring a complex of flavonoid and aluminum at $510 \mathrm{~nm}$ by the method of Cvek et al. (2007). Flavonoid content was determined by plotting a standard curve using different concentrations of naringenin. Flavonoid content was expressed in $\mathrm{mg} / \mathrm{g}$ of extract.

\section{In vivo safety evaluation}

\section{Animals and chemicals}

A total of 48 female Wistar rats (10-12 weeks old; $180 \pm 20 \mathrm{~g})$ were procured from the Defense Research and Development Establishment, Gwalior, India. All animal procedures were approved by the Institutional Animal Ethics Committee (994/Ere/GO/06/CPCSEA). Rats were kept in contamination-free environment at $\left(25^{\circ} \mathrm{C} \pm 2{ }^{\circ} \mathrm{C}\right)$ temperature, 12 hours dark-light cycle, and relative humidity of $60 \%-70 \%$. A standard pelleted diet with free access to tap water was provided to rats. Animals were acclimatized for 10 days before the commencement of experiments. Pure and analytical grade chemicals acquired from standard chemical suppliers were used in the present study.

\section{No-observed-adverse-effect-level (NOAEL)}

For estimation of NOAEL rats were randomly assigned to five groups containing six animals. Group 1 served as control (gavaged with normal saline), Groups II-V were administered with $H$. indicus root extract at 100, 200, 400, and $800 \mathrm{mg} / \mathrm{kg}$ body weight doses, respectively, for 7 days (Sandhiya and Ubaidulla, 2017). All the animals were weighed and partially anesthetized with sodium pentobarbitone after 24 hours of last treatment. Blood was collected by retro-orbital puncture and allowed to clot in test tubes for 30 minutes at room temperature. Clotted blood was centrifuged for 20 minutes at $375 \mathrm{~g}$ for serum isolation and stored at $-20^{\circ} \mathrm{C}$ (Riley, 1960). Various parameters of liver function tests, i.e., alanine aminotransferase, aspartate aminotransferase alkaline phosphatase, bilirubin, triglycerides, cholesterol and kidney function tests, i.e., urea, uric acid, and creatinine were performed using standard commercial Kits (Erba Diagnostics, Germany) according to the manufacturer's instructions. 
Table 1. Qualitative phytochemical evaluation of $H$. indicus ethanolic extract.

\begin{tabular}{ccccc}
\hline Sl. no. & Phytochemical & Leaf & Stem & Root \\
\hline 1 & Alkaloids & Present & Present & Present \\
2 & Flavonoids & Present & Present & Present \\
3 & Tannins & Present & Present & Present \\
4 & Saponins & Present & Present & Present \\
5 & Terpenoids & Present & Present & Present \\
6 & Carbohydrate & Present & Present & Present \\
7 & Glycosides & Present & Present & Present \\
8 & Proteins & Present & Present & Present \\
\hline
\end{tabular}

\section{Choleretic activity}

For the estimation of choleretic activity, female rats were divided into three groups of six animals each. Group 1 served as control, administered with normal saline at $2 \mathrm{ml} / \mathrm{kg}$, id, Group 2 received dihydrocholic acid (DHC) as standard $(50 \mathrm{mg} / \mathrm{kg}$, id), and Group 3 administered with $H$. indicus $(400 \mathrm{mg} / \mathrm{kg}$, id). Animals were anesthetized with urethane $(25 \%, 6 \mathrm{ml} / \mathrm{kg}$, ip) after 12 hours fasting period. The bile duct was surgically exposed by midline incision $(25 \mathrm{~mm})$ and cannulated close to the duodenum with PE-10 tubing. The rectal temperature of anesthetized rats was maintained at $37^{\circ} \mathrm{C}$. Bile was collected for an hour separately in all three groups and at the end of the first hour, rats were administered with normal saline (Group 1), DHC (Group 2 ), and root extract of $H$. indicus (Group 3). Bile was collected for 2-5 hours followed by administration of normal saline, standard, and extract. Total bile volume was measured after the end of the fifth hour and kept for drying at room temperature. Bile solid content was determined by evaporating samples to dryness and weight of residue was recorded (Klaassen and Plaa, 1969).

\section{Statistical analysis}

Results were expressed as the mean \pm standard error of six animals used in each group. The Student's $t$-test was used to compare mean values of different parameters obtained in various groups and $* p \leq 0.05$ was considered as significant. Data were subjected to statistical analysis by using Microsoft Excel 2013 (15.0.4420.1017) 32-bit, India through one-way analysis of $F$ variance (ANOVA).

\section{RESULTS AND DISCUSSION}

\section{Qualitative and quantitative phytochemical evaluation}

Antioxidant properties of plants due to the presence of phytochemicals have gained much interest in pharmaceutical research (Saha et al., 2018). Presence of polyphenolic compounds in plants contributes to medicinal properties. Phenolic $\mathrm{OH}$ group is vital for both antioxidant activity and free radical kinetics, it may contribute directly in entrapments of singlet and triplet oxygen radicals (Fergusion et al., 2006; Priyadarsini et al., 2003). Hemidesmus indicus is a well-known medicinal plant with a high concentration of bioactive components (Ananthi et al., 2010). Phytochemicals present in root extract of $H$. indicus possess free radical hunting property (Ravishankara et al., 2002; Saravanan and Nalini, 2007). Preliminary qualitative phytochemical evaluation of $H$. indicus leaf, stem, and root extract revealed the
Table 2. Quantitative phytochemical evaluation of $H$. indicus ethanolic extract.

\begin{tabular}{cccc}
\hline $\begin{array}{c}\text { Phytochemical } \\
\text { (per gram of } \\
\text { extract) }\end{array}$ & Leaf $(\mathbf{m g} / \mathbf{g})$ & Stem $(\mathbf{m g} / \mathbf{g})$ & Root $(\mathbf{m g} / \mathbf{g})$ \\
\hline Polyphenols & 45.5 & 46.7 & 57.7 \\
Flavonoids & 12.2 & 22.3 & 27.3 \\
Flavonones & 4.80 & 3.69 & 7.16 \\
Flavones and & 0.32 & 0.62 & 0.69 \\
flavonols & & & \\
\hline
\end{tabular}

presence of alkaloids, flavonoids, tannins, saponins, terpenoids, carbohydrate, glycosides, and proteins (Table 1). The amount of total polyphenolic content in $H$. indicus was found to be 45.5, 46.7 , and $57.7 \mathrm{mg} / \mathrm{g}$ of extract in leaf, root, and stem, respectively. Total flavonoid content was observed to be the highest in root extract of $H$. indicus $(27.3 \mathrm{mg} / \mathrm{g}$ of extract) followed by the stem $(22.3 \mathrm{mg} / \mathrm{g}$ of extract), and leaf $(12.2 \mathrm{mg} / \mathrm{g}$ of extract). Total flavonone was found to be $4.80,3.69$, and $7.16 \mathrm{mg} / \mathrm{g}$ of extract in leaf, stem, and root, respectively. Total flavone and flavonol content in leaf were very less $(0.32 \mathrm{mg} / \mathrm{g}$ of extract $)$ as compared with the stem $(0.62 \mathrm{mg} / \mathrm{g}$ of extract $)$ and root $(0.69 \mathrm{mg} / \mathrm{g}$ of extract $)$. The $H$. indicus extract showed the highest concentration of polyphenolic content followed by flavonoids, flavonones, flavones, and flavonols in root as compared with leaf and stem, respectively (Table 2). Thus, a root extract of the plant may hold better therapeutic applications (Kundu and Mitra, 2014).

The high concentration of phenolic compounds in the plant might be responsible for its strong antioxidant property. Secondary metabolites of plants are reported to have many biological and therapeutic properties (Benedec et al., 2013; Charalamposetal., 2013; Narender etal.,2012; Vishnuetal.,2013). The presence of phytochemicals such as phenols, tannins, and flavonoids in $H$. indicus extract might give approval to its local usage in the treatment of various diseases (Gopi and Setty, 2010). Traditionally, tannins have been used for detoxification and treatment of wound healing, diarrhea, and hemorrhage (Afolayan and Mabebie, 2010; Okwu and Emenike, 2006). The methanolic extracts of the plant are reported to protect plasmid DNA from strand breaks and reduced damage due to lipid peroxidation in microsomes of rat liver (Shetty et al., 2005). Flavonoids are an important secondary metabolite of plants and well-known for their antioxidant activity (Shi et al., 2006). The ethnomedicinal usage of $H$. indicus extract for management of oxidative stressinduced diseases might be due to the high concentration of flavonoids (Ammar et al., 2008; Kostova, 2005). Flavonoids help to preserve membrane permeability of cell by inhibition of ATPase and phospholipase A2 enzymes (Li et al., 2003). Free radicals are inactivated by flavonoids by the formation of stable and less toxic product (Dureja and Dhiman, 2012; Korkina and Afanas'ev, 1997). Thus, the use of $H$. indicus in the treatment of free radical associated diseases, i.e., arthritis and rheumatic disease is well justified (Mehta et al., 2012). Terpenoids are known to have anti-allergenic, antispasmodic, antihyperglycemic, antiinflammatory, antiviral, antimicrobial, antifungal, antiparasitic, and immunomodulatory effect (Rabi et al., 2009; Wagner and Elmadfa, 2003). Saponins possess blood coagulating property (Okwu, 2004). Interestingly, both terpenoids and saponins are present in H. indicus (Aneja et al., 2008; Austin, 2008; 


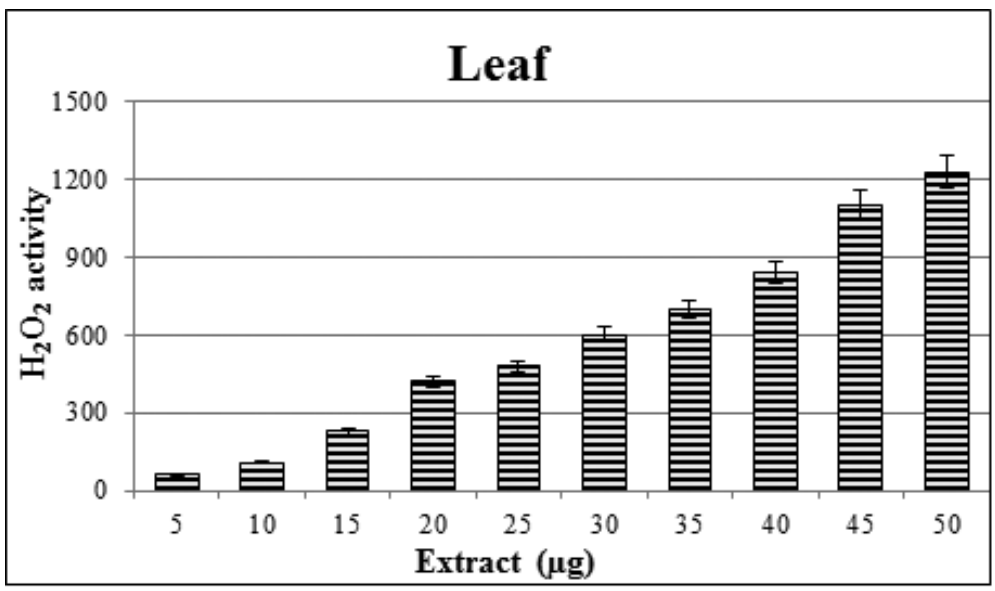

A

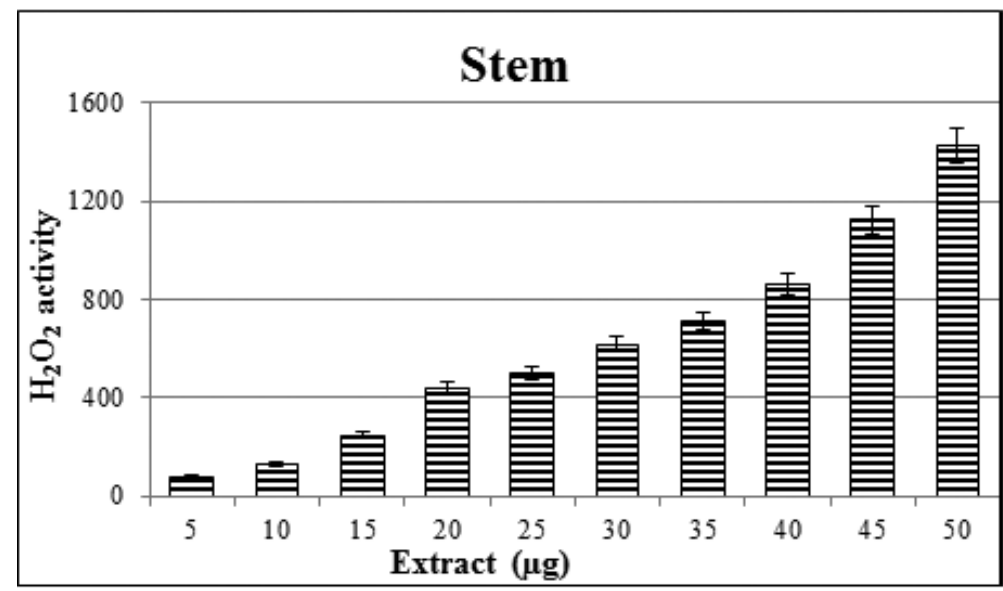

B

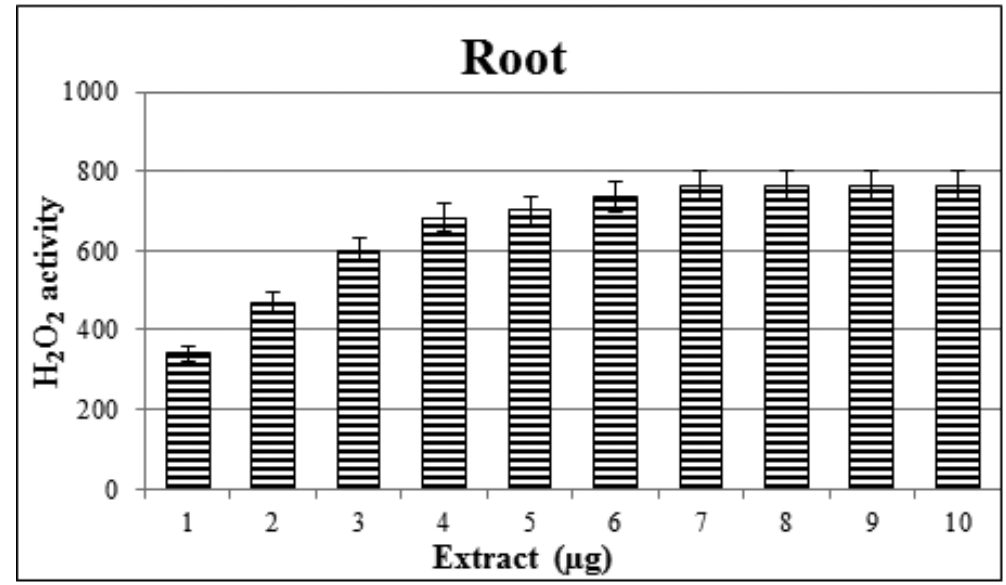

$\mathrm{C}$

Fig 1. Hydrogen peroxide scavenging activity of $H$. indicus leaf (A), stem (B) and root (C) extract. (Data are expressed as mean \pm SE at $5 \%, n=6$ ).

George et al., 2008). Phytochemicals like carbohydrates and glycosides were also observed in the plant extract (Austin, 2008; Sigler et al., 2000), which are known to improve the immune system (Theis and Lerdau, 2003). The extract of $H$. indicus contains proteins, the building blocks of life which help to repair and maintain cells (Ojala et al., 2000). Previous reports suggests that alcoholic extract of its roots possesses antihepatotoxic, renoprotective, anti-inflammatory, antithrombotic, antidiarrheal, antinociceptive, and antienterobacterial activities (Baheti et al., 2006; Das and Devaraj, 2006; Das et al., 2003; Kotnis et al., 2004; Mary et al., 2003; Prabakan et al., 2000; Saravanan and Nalini, 2008; Verma et al., 2005). 
Table 3. Serum biochemical values of rats treated with $H$. indicus root extract for a week.

\begin{tabular}{ccccc}
\hline Concentration of extract $(\mathbf{m g})$ & ALT (IU/l) & AST (IU/l) & ALP(IU/I) & Bilirubin (mg/dl) \\
\hline Control & $32.2 \pm 2.82$ & $75.4 \pm 3.89$ & $430 \pm 32.2$ & $0.23 \pm 0.01$ \\
100 & $34.1 \pm 2.82$ & $76.7 \pm 4.78$ & $428 \pm 29.6$ & $0.26 \pm 0.02$ \\
200 & $31.8 \pm 2.39$ & $79.5 \pm 4.48$ & $418 \pm 29.6$ & $0.23 \pm 0.01$ \\
400 & $34.2 \pm 3.05$ & $85.5 \pm 4.75$ & $370 \pm 20.4$ & $0.20 \pm 0.01$ \\
800 & $37.5 \pm 2.79$ & $90.2 \pm 6.45$ & $395 \pm 21.8$ & $0.24 \pm 0.01$ \\
$F$ variance & $0.71^{\mathrm{ns}}$ & $1.68^{\text {ns }}$ & $1.52^{\mathrm{ns}}$ & $0.46^{\mathrm{ns}}$ \\
\hline
\end{tabular}

Data are expressed as mean $\pm \mathrm{SE} ; n=6$; ${ }^{*}$ Significant $p$ value Therapy $v$. control at $5 \%$; ns $=$ not significant $F$ variance at $5 \%$. ALT $=$ alanine aminotransferase AST $=$ aspartate aminotransferase; ALP $=$ alkaline phosphatase.

\section{Hydrogen peroxide scavenging activity}

The $\mathrm{H}_{2} \mathrm{O}_{2}$ penetrates plasma membranes of the cell where it converted into highly reactive hydroxyl radical (Gulcin et al., 2003). Medicinal plants are the best-known scavenger of free radicals with negligible adverse effects (Naidoo et al., 2016). Scavenging of hydrogen peroxide by $H$. indicus leaf, stem, and root extracts might be attributed to the presence of polyphenolic compounds, which contribute electron to hydrogen peroxide, thus reducing it to water. All the three parts of plant extract efficiently scavenged hydrogen peroxide in a concentration-dependent manner, however, the root extract showed better scavenging activity as compared with leaf and stem due to the presence of the highest amount of flavonoid contents [(Fig.s 1(A)-(C)].

\section{No-observed-adverse-effect-level}

The no-observed-adverse-effect-level is an essential part of non-clinical drug hazard evaluation and is defined as adverse reactions occurring instantaneously or in a short period of time after administration of any drug (Dorato and Engelhardt, 2005). Determination of serum biochemical parameters could be used to reveal the harmful effect of foreign substances, including plant extracts. It includes the evaluation of possible variations in enzymes, metabolic products, and functioning of organs (Olson et al., 2000). The liver plays a vital role in the metabolism and detoxification of harmful substances. Therefore, the liver is a potent target organ of toxic insult from drugs (Shah et al., 2011). In the present study, 1- week administration of $H$. indicus root extract at 100, 200, 300, 400, and $800 \mathrm{mg} / \mathrm{kg}$ brought no significant change in the level of liverrelated enzymes, which is an indication of no cellular damage by the plant extract. An elevated level of aspartate aminotransferase, alanine aminotransferase, and alkaline phosphatase in serum may designate cellular outflow and damages functional integrity of the cell membrane in the liver as a result of metabolism of toxic substances (Ozer et al., 2008). Ethanolic root extract of
H. indicus at all doses $(100,200,300,400$, and $800 \mathrm{mg} / \mathrm{kg}) \mathrm{did}$ not show significant alteration in total bilirubin (Table 3 ). The concentration of bilirubin reveals the amount of conjugated and unconjugated bilirubin. Total bilirubin levels are mostly increased in various types of hepatic diseases, i.e., blockades in a hepatobiliary system such as gallstones or tumors, cirrhosis, hepatitis (Burtis and Ashwood, 1999). Bilirubin content not significantly altered after $H$. indicus treatment might be due to the tendency of the plant extract to enhance the excretion of bilirubin through bile. Enhancement of non-essential fatty acids occurs during oxidative stress and disturbed lipid metabolism, which in turn upsurges triglycerides and cholesterol levels in serum (Bhadauria et al., 2008). Administration of $H$. indicus root extract slightly altered triglycerides and cholesterol content showing no adverse effect on the metabolic activity of the liver.

The kidney is responsible for conserving homeostatic balance of body by reabsorbing essential material and eliminating waste products (James et al., 2010). Kidney functions are generally determined by assessment of urea, uric acid, and creatinine level in blood. Creatinine is formed in muscles by metabolism of creatine. It is synthesized in the liver, passes into blood circulation, and is taken up by skeletal muscle (Gowda et al., 2010). However, the retention of creatinine in blood is an indication of renal disease. Creatinine level was slightly elevated at a dose of $800 \mathrm{mg} / \mathrm{kg}$ but the increase was not significant as compared with control, which is a clear signal of effective removal of the extract by the kidneys without any adverse effect (Eaton and Pooler, 2009). Tubular necrosis, liver ailments, and the incomplete absorption of proteins may cause increased serum urea (Burti et al., 2006). Uric acid is the metabolic product of purines, excreted into urine. The increased level of uric acid reduces renal blood flow and hampers the glomerular filtration rate. In the present study, there was no substantial change in urea and uric acid levels at all the doses of $H$. indicus indicating that the root extract is harmless to use as a therapeutic agent up to $800 \mathrm{mg} / \mathrm{kg}$ dose (Table 4).

Table 4. Serum biochemical values of rats treated with $H$. indicus root extract for a week.

\begin{tabular}{|c|c|c|c|c|c|}
\hline Concentration of extract (mg) & Triglycerides (mg/dl) & Cholesterol (mg/dl) & Urea (mg/dl) & Uric acid (mg/dl) & Creatinine (mg/dl) \\
\hline Control & $28.1 \pm 1.96$ & $10.2 \pm 0.68$ & $28.6 \pm 2.33$ & $1.43 \pm 0.08$ & $0.68 \pm 0.04$ \\
\hline 100 & $31.8 \pm 1.98$ & $10.3 \pm 0.56$ & $33.2 \pm 2.09$ & $1.21 \pm 0.08$ & $0.64 \pm 0.04$ \\
\hline 200 & $32.6 \pm 2.10$ & $10.6 \pm 0.55$ & $35.1 \pm 2.56$ & $1.18 \pm 0.08$ & $0.66 \pm 0.05$ \\
\hline 400 & $30.4 \pm 1.84$ & $9.29 \pm 0.51$ & $34.3 \pm 2.82$ & $1.28 \pm 0.11$ & $0.65 \pm 0.05$ \\
\hline 800 & $33.0 \pm 2.05$ & $9.62 \pm 0.52$ & $36.5 \pm 3.19$ & $1.32 \pm 0.11$ & $0.75 \pm 0.06$ \\
\hline$F$ variance & $1.83^{\mathrm{ns}}$ & $1.03^{\mathrm{ns}}$ & $1.57^{\mathrm{ns}}$ & $1.26^{\mathrm{ns}}$ & $0.86^{\mathrm{ns}}$ \\
\hline
\end{tabular}


Table 5. Effect of $H$. indicus root extract on the choleretic activity of rat.

\begin{tabular}{|c|c|c|c|c|c|c|}
\hline \multirow{2}{*}{ Treatment } & \multicolumn{3}{|c|}{ Bile flow (ml) } & \multicolumn{3}{|c|}{ Bile solid (mg) } \\
\hline & 1 hour & 2-5 hours & Ratio & 1 hour & $2-5$ hour & Ratio \\
\hline Control & $0.65 \pm 0.03$ & $1.68 \pm 0.10$ & $1: 2.58$ & $19.9 \pm 1.68$ & $49.0 \pm 3.08$ & $1: 2.46$ \\
\hline DHC (50 mg/kg) & $0.56 \pm 0.03$ & $2.05 \pm 0.17$ & $1: 3.66$ & $18.2 \pm 1.41$ & $58.3 \pm 4.85$ & $1: 3.20$ \\
\hline H. indicus $(400 \mathrm{mg} / \mathrm{kg})$ & $0.62 \pm 0.04$ & $1.79 \pm 0.10$ & $1: 2.89$ & $20.1 \pm 1.52$ & $55.9 \pm 3.73$ & $1: 2.78$ \\
\hline$F$ variance & $1.73^{\text {ns }}$ & $2.50^{\mathrm{ns}}$ & & $0.76^{\mathrm{ns}}$ & $1.78^{\mathrm{ns}}$ & \\
\hline
\end{tabular}

Data are expressed as mean $\pm \mathrm{SE} ; n=6$; $*$ Significant $p$ value Therapy $v s$. control at $5 \%$; ns $=$ not significant $F$ variance at $5 \%$. DHC $=$ dihydrocholic acid (standard).

\section{Choleretic activity}

The liver is involved in secretion and stimulation of normal bile flow and determination of choleretic activity of any therapeutic agent is a worthy pointer for safety evaluation (Bhadauria et al., 2007). Cholic acid is an essential bile acid found in mammals, thus in the present study, dehydrocholic acid was used as a standard. The decrease in bile flow was observed from the first hour and second- to the fifth hour. It was found that DHC $(50 \mathrm{mg} / \mathrm{kg})$ and H. indicus $(400 \mathrm{mg} / \mathrm{kg})$ treated rats had more bile outputs during 2-5 hours period as compared with control. Hemidesmus indicus administration increased bile volume during 2-5 hours which indicated its choleretic activity. The excretion of total solids was observed for five consecutive hours. Hemidesmus indicus increased excretion of bile solid content during 2-5 hours comparable with the standard drug DHC (Table 5). Present study showed an upsurge in bile flow and bile solids under the influence of $H$. indicus is suggestive of its stimulatory action on secretary activity of hepatic cells. Phenolic compounds have been associated with choleretic activity in animals (Mortier, 1972). Their metabolites are secreted in bile as an organic anion coupled with $\mathrm{Na}^{+}$or $\mathrm{K}^{+}$and water is passively excreted (Takeda and Aburada, 1981). Phytochemical analysis in the present study confirmed the presence of terpenes, polyphenol, and flavonoids could be involved in the choleretic activity (Hoefler et al., 1987). Present study is in corroboration with findings of other plant extracts (Chandan et al., 2008; Mittal et al., 2012).

\section{CONCLUSION}

Hemidesmus indicus may be a potent therapeutic agent due to the presence of a plethora of secondary metabolites such as flavonoids, tannins, alkaloids, carbohydrates, polyphenols, saponins, glycosides, terpenoids, and proteins. The strong correlation between the contents of total polyphenols, flavonoids, flavonones, flavone and flavonols, and radical scavenging activity indicates that these phytochemical constituents are responsible for the antioxidant potential of the plant. Root extract possesses the highest amount of bioactive components as compared with stem and leaf. NOAEL of $H$. indicus root extract is $800 \mathrm{mg} / \mathrm{kg}$ dose. The antioxidant and choleretic activity of the plant provides a satisfactory rationale for its hepatoprotective activity. Hemidesmus indicus may be helpful in improving the adherence to hepatotoxic drugs and its clinical outcome.

\section{ACKNOWLEDGMENTS}

Financial assistance was provided by University Grants Commission, New Delhi (UGC-MRP, F.42-520/2013 SR), Guru Ghasidas University, Bilaspur for providing non-NET fellowship,
Department of Rural Technology and Social Development for providing extraction facility are gratefully acknowledged.

\section{CONFLICT OF INTEREST}

The authors declare that they have no competing interest.

\section{REFERENCES}

Afolayan AJ, Mabebie BO. Ethnobotanical study of medicinal plants used as anti-obesity remedies in Nkonkobe Municipality of South Africa. Pharmacogn J, 2010; 2:368-73.

Ammar RB, Kilani S, Bouhlel I, Ezzi L, Skandrani I, Boubaker J, Sghaier MB, Naffeti A, Mahmoud A, Chekir-Ghedira L, Ghedira K Antiproliferative. antioxidant and antimutagenic activities of flavonoid enriched extracts from (Tunisian) Rhamnusalaternus L.: combination with the phytochemical composition. Drug Chem Toxicol, 2008; 31:61-80.

Ananthi R, Chandra N, Santhiya ST, Ramesh A. Genotoxic and antigenotoxic effects of Hemidesmus indicus $\mathrm{R}$. Br. root extract in cultured lymphocytes. J Ethnopharmacol, 2010; 127:558-60.

Aneja V, Suthar A, Verma S, Kalkunte S. Plant review phytopharmacology of Hemidesmus indicus. Pharmacogn Rev, 2008; $2: 143-50$

Austin A. A review of Indian Sarasaparilla, Hemidesmus indicus (L.) R. Br. J Biol Sci, 2008; 8:1-12.

Azwanida NN. A review on the extraction methods use in medicinal plants, principle, strength and limitation. Med Aromat Plants, 2015; 4:196.

Baheti JR, Goyal RK, Shah GB. Hepatoprotective activity of Hemidesmus indicus R. Br. in rats. Indian J Exp Biol, 2006; 44:399-402.

Benedec D, Vlase L, Oniga I, Mot AC, Damian G, Hanganu D, Duma M, Silaghi-Dumitrescu R. Polyphenolic composition, antioxidant and antibacterial activities for two Romanian subspecies of Achilleadistans Waldst. et Kit. ex Wild. Molecules, 2013; 18:8725-39.

Bhadauria M, Nirala SK, Shukla S. Multiple treatments of propolis extract ameliorates carbon tetrachloride induced liver injury in rats. Food and Chemi Toxicol, 2008; 46:2703-12.

Bhadauria M, Nirala SK, Shukla S. Propolis protects CYP 2E1 enzymatic activity and oxidative stress induced by carbon tetrachloride. Mol Cell Biochem, 2007; 302:215-24.

Burti CA, Ashwood ER, Bruns DE, Saunders WB. Textbook of Clinical Chemistry. vol. 24, 4th edition, Philadelphia Company, United States, pp 801-3, 2006.

Burtis CA, Ashwood ER. Textbook of clinical chemistry and laboratory medicine. 3rd edition, W.B. Saunders Company 1915, Philadelphia PA, 1999.

Chandan BK, Saxena AK, Shukla S, Sharma N, Gupta DK, Singh K, Suri J, Bhadauria M, Qazi GN. Hepatoprotective activity of Woodfordia fruticosa Kurz flowers against carbon tetrachloride induced hepatotoxicity. J Ethnopharmacol, 2008; 119:218-24.

Charalampos P, Konstantina L, Olga KM, Panagiotis Z, Vassileia JS. Antioxidant capacity of selected plant extracts and their essential oils. Antioxidants, 2013; 2:11-22.

Cvek J, Medic-saric M, Jasprica I. Optimization of an extraction procedure and chemical characterization of creation propolis tinctures. Phytochem Anal, 2007; 18:451-9. 
Das S, Devaraj SN. The antienterobacterial activity of Hemidesmus indicus R.Br. root extract. Phytother Res, 2006; 20:416-21.

Das S, Prakash R, Devaraj SN. Anti-diarrhoeal effects of methanolic root extract of Hemidesmus indicus (Indian sarsaparilla) - an in vitro and in vivo study. Indian J Exp Biol, 2003; 41:363-6.

De Smet PM. Health risk of herbal remedies. Drug Saf, 1995; 13:81-93.

Dorato MA, Engelhardt JA. The no-observed adverse- effectlevel in drug safety evaluations: use, issues, and definition(s). Regul Toxicol Pharmacol, 2005; 42:265-74.

Dureja AG, Dhiman K. Free radical scavenging potential and total phenolic and flavonoid content of Ziziphus mauritiana and Ziziphus nummularia fruit extracts. Int J Green Pharm, 2012; 6:187-92.

Eaton DC, Pooler JP. Vander's physiology. 7th edition, McGrawHill Lange, New York, United States, pp 230-367, 2009.

Fabricant DS, Farnsworth NR. The value of plants used in traditional medicine for drug discovery. Environ Health Perspect, 2001; 109:69-75.

Fergusion LR, Philpott M, Karuna singhe N. Oxidative DNA damage and repair: significance and biomarkers. J Nutr, 2006; 136:2687S-9S.

Ferruzzi L, Turrini E, Burattini S, Falcieri E, Poli F, Mandrone M, Sacchetti G, Tacchini M, Guerrini A, Gotti R, Hrelia P, CantelliForti G, Fimognari C. Hemidesmus indicus induces apoptosis as well as differentiation in a human promyelocytic leukemic cell line. J Ethnopharmacol, 2013; 147:84-91.

Fibigr J, Satinsky D, Solich P. Current trends in the analysis and quality control of food supplements based on plant extracts. Anal Chim Acta, 2018; doi: 10.1016/j.aca.2018.08.017. Volume 1036, Pages 1-15

Fimognari C, Lenzi M, Ferruzzi L, Turrini E, Scartezzini P, Poli F, Gotti R, Guerrini A, Carulli G, Ottaviano V, Cantelli-Forti G, Hrelia P. Mitochondrial pathway mediates the antileukemic effects of Hemidesmus indicus, a promising botanical drug. PLoS One, 2011; 6:e21544.

George S, Tushar KV, Unnikrishnan KP, Hashim KM, Balachandran I. Hemidesmus indicus (L.) R. Br. A review. J Plant Sci, 2008; 3:146-56.

Gopi S, Setty OH. The beneficial effect of the administration of Hemidesmus indicus against bromobenzene induced oxidative stress in rat liver mitochondria. J Ethnopharmacol, 2010; 127:200-3.

Gowda S, Desai PB, Kulkarni SS, Hull VV, Math AA, Vernekar SN. Markers of renal function tests. N Am J Med Sci, 2010; 2:170-3.

Gulcin I, Oktay M, Kirecci E, Kufrevioglu OI. Screening of antioxidant and antimicrobial activities of anise (Pimpinella anisum L) seed extracts. Food Chem, 2003; 83:371-82.

Harbone JB. Phytochemical methods. Chappnan and Hall Ltd. London, UK, pp 49-188, 1973.

Hoefler C, Flexjrentin J, Mortiex F, Pelp JM, Guillemain J. Comparative choleretic and hepatoprotective properties of young sprouts and total plant extracts of Rosmarinus officinalis in rats. J Ethnopharmacol, $1987 ; 19: 133-43$

James D, Elebo N, Sanusi AM, Odoemene L. Some biochemical effect of intraperitoneal administration of Phyllanthus amarus aquoeus extracts on normaglycemic Albino rats. Asian J Med Sci, 2010; 2:7-10.

Klaassen CD, Plaa GL. Effect of carbon tetrachloride on the metabolism, storage and excretion of sulfobromophthalein. Toxicol Appl Pharmacol, 1969; 12:132-9.

Korkina LG, Afanas'ev IB. Antioxidant and chelating properties of flavonoids. Adv Pharmacol, 1997; 38:151-63.

Kostova I. Synthetic and natural coumarins as cytotoxic agents. Curr Med Chem Anticancer Agents, 2005; 5:29-46.

Kotnis MS, Patel P, Menon SN, Sane RT. Renoprotective effect of Hemidesmus indicus, a herbal drug used in gentamicin induced renal toxicity. Nephrol (Carlton), 2004; 9:142-52.

Kundu A, Mitra A. Evaluating tyrosinase (monophenolase) inhibitory activity from fragrant roots of Hemidesmus indicus for potent use in herbal products. Ind Crops Prod, 2014; 52:394-9.
Li H, Wang Z, Liu Y. Review of the studies on tannins activity of cancer prevention and anticancer. Zhong Yao Cai, 2003; 26:444-8.

Mary NK, Achuthan $\mathrm{CR}$, Babu $\mathrm{BH}$, Padikkala J. In vitro antioxidant and antithrombotic activity of Hemidesmus indicus (L) R.Br. J Ethnopharmacol, 2003; 87:187-91.

Mehta A, Sethiya NK, Mehta C, Shah GB. Anti-arthritis activity of roots of Hemidesmus indicus R.Br. (Anantmul) in rats. Asian Pac J Trop Med, 2012; 5:130-5.

Mittal DK, Joshi D, Shukla S. Antioxidant, antipyretic and choleretic activities of crude extract and an active compound of Polygonum Bistorta (Linn.) in albino rats. Int J Pharma Biol Sci, 2012; 2:25-31.

Mortier F. Therapeutic interest of certain aliphatic organic acids constituents of various drugs with hepatorenal reputation and in particular of Cynara scolymus L. These Pharmacy, University of Nancy, France, p 200, 1972

Naidoo Y, Sadashiva CT, Naidoo G, Raghu K. Antibacterial, antioxidant and phytochemical properties of the ethanolic extract of ocimum obvatum E. Mey, ex Benth. Indian J Tradit Knowle, 2016; 15:57-61.

Nair SA, Sabulal B, Radhika J, Arunkumar R, Subramoniam A. Promising anti-diabetes mellitus activity in rats of $\beta$-amyrin palmitate isolated from Hemidesmus indicus roots. Eur J Pharmacol, 2014; 734:7782

Narender PD, Ganga R, Sambasiva E, Mallikarjuna T, Praneeth VS. Quantification of phytochemical constituents and in vitro antioxidant activity of Mesuaferrea leaves. Asian Pac J Trop Biomed, 2012; 2:S539-42.

Ojala T, Remes S, Haansuu P, Vuorela H, Hiltunen R, Haahtela K, Vuorela P. Antimicrobial activity of some coumarin containing herbal plants growing in Finland. J Ethnopharmacol, 2000; 73:299-305.

Okwu DE, Emenike IN. Evaluation of the phytonutrients and vitamin contents of citrus fruits. Int J Mol Med Adv Sci, 2006; 2:1-6.

Okwu DE. Phytochemicals and vitamin content of indigenous spices of south-eastern Nigeria. J Sustain Agric Environ, 2004; 6:30-7.

Olson H, Betton G, Robinson D, Thomas K, Monro A, Kolaja G, Lilly P, Sanders J, Sipes G, Bracken W, Dorato M, Van Deun K, Smith P, Berger B, Heller A. Concordance of toxicity of pharmaceuticals in humans and in animals. Reg Toxicol Pharmacol, 2000; 32:56-67.

Ozer J, Ratner M, Shaw M, Bailey W, Schomaker S. The current state of serum biomarkers of hepatotoxicity. Toxicol, 2008; 245:194-205.

Pal SK, Shukla Y. Herbal Medicine: current status and the future. Asian Pac J Cancer Prev, 2003; 4:281-88.

Park M, Choi H, Kim J, Lee H, Ku S. 28 days repeated oral dose toxicity test of aqueous extracts of Mahwanguoun pae-tang, a polyherbal formula. Food Chem Toxicol, 2010; 48:2477-82.

Prabakan M, Anandan R, Devaki T. Protective effect of Hemidesmus indicus against rifampicin and isoniazid induced hepatotoxicity in rats. Fitoterapia, 2000; 71:55-9.

Priyadarsini KI, Maity DK, Naik GH, Kumar MS, Unnikrishnan MK, Satav JG, Mohan H. Role of phenolic $\mathrm{OH}$ and methylene hydrogen on the free radical reactions and antioxidant activity of curcumin. Free Radic Biol Med, 2003; 35:475-84.

Qureshi S, Rai MK, Agrawal SC. Hindustan. Antibiot Bull, 1997; 39:56e-60e.

Rabi T, Bishayee A. Terpenoids and breast cancer chemoprevention. Breast Cancer Res Treat, 2009; 115:223-39.

Ravishankara MN, Shrivastava N, Padh H, Rajani M. Evaluation of antioxidant properties of root bark of Hemidesmus indicus $\mathrm{R}$. Br. (Anantmul). Phytomedicine, 2002; 9:153-60.

Riley V. Adaptation of orbital bleeding technique to rapid serial blood studies. Proc Soc Exp Biol Med, 1960; 104:751-4.

Ruch RJ, Cheng SJ, Klaving JF. Prevention of cytotoxicity and inhibition of intracellular communication by antioxidant catechins isolated from chinese green tea. Carcinogenesis, 1989; 10:1003-8.

Saha MR, Kar P, Sen A. Assessment of phytochemical, antioxidant and genetic diversities among selected medicinal plant species of Mimosoideae (Mimosaceae). Indian J Tradit Knowle, 2018; 17 $132-40$ 
Samarakoon SR, Thabrew I, Galhena PB, Tennekoon KH. Modulation of apoptosis in human hepatocellular carcinoma (HepG2cells) by a standardized herbal decoction of Nigella sativa seeds, Hemidesmus indicus roots and Smilax glabra rhizomes with anti-hepatocarcinogenic effects. BMC Complement Altern Med, 2012; 12:25.

Sandhiya V, Ubaidulla U. Role of secondary metabolite from the root of Hemidesmus indicus against psoriasis (via) semisolid dosage form. Pharma Sci Monit, 2017; 8:93-107.

Saravanan N, Nalini N. Antioxidant effect of Hemidesmus indicus on ethanol induced hepatotoxicity in rats. J Med Food, 2007; 10:675-82.

Saravanan N, Nalini N. Hemidesmus indicus protects against ethanol induced liver toxicity. Cell Mol Biol Lett, 2008; 13:20-37.

Shah R, Parmar S, Bhatt P, Chandra S. Evaluation of hepatoprotective activity of ethyl acetate fraction of "Tephrosia purpurea." Pharmacol Online, 2011; 3:188-94.

Shetty TK, Satav JG, Nair CKK. Radiation protection of DNA and membrane in vitro by an extract of Hemidesmus indicus. Phytother Res, 2005; 19:387-390.

Shi J, Yu J, Pohorly J, Young C, Bryan M, Wu Y. Optimization of the extraction of polyphenols from grapes seed meal by aqueous ethanol solution. Food Agric Environ, 2006; 1:42-7.

Sigler P, Saksena R, Deepak D, Khare A. C21 steroidal glycosides from Hemidesmus indicus. Phytochemistry, 2000; 54:983-7.

Slinkard K, Singleton VL. Total phenol analysis: automation and comparison with manual methods. Am J Enol Vitic, 1997; 28:49-55.

Takeda S, Aburada M. The choleretic mechanism of coumarin compounds and phenolic compounds. J Pharmaco biodyn, 1981; 4:724-34.

Theis N, Lerdau M. The evolution of function in plant secondary metabolites. Int J Plant Sci, 2003; 164:S93-103.

Trease GE, Evans WC. Pharmacognocy. 13th edition, Balliere Tindall, London, UK, pp 176-80, 1989.
Turrini E, Ferruzzi L, Guerrini A, Gotti R, Tacchini M, Teti G, Falconi M, Hreliac P, Fimognari C. In vitro anti-angiogenic effects of Hemidesmus indicus in hypoxic and normoxic conditions. J Ethnopharmacol, 2015; 162:261-9.

Verma PR, Joharapurkar AA, Chatpalliwar VA, Asnani AJ. Antinociceptive activity of alcoholic extract of Hemidesmus indicus R.Br. in mice. J Ethnopharmacol, 2005; 102:298-301.

Vishnu R, Nisha R, Jamuna S, Paulsamy S. Quantification of total phenolics and flavonoids and evaluation of in vitro antioxidant properties of methanolic leaf extract of Tarenna asiatica - an endemic medicinal plant species of Maruthamali hills, Western Ghats, Tami Nadu. J Res Plant Sci, 2013; 2:196-204.

Wagner KH, Elmadfa I. Biological relevance of terpenoids: Overview focusing on mono-di and tetraterpenes. Ann Nutr Metab, 2003 47:95-106.

Wang Y, Wang L, Zhu X, Wang D, Li X. The choleretic activity of Turmeric and its active ingredients. J Food Sci, 2016; H1-7.

Zarei M, Javarappa KK. The anticarcinogenic and cytotoxic potential of Hemidesmus indicus root extract against Ehrlich Ascites tumor. Der Pharm Lett, 2012; 4:906-10.

\section{How to cite this article:}

Mishra G, Chandra HK, Sahu N, Nirala SK, Bhadauria M. Preliminarily phytochemical screening and in vivo safety evaluation of ethanolic extract of Hemidesmus indicus (Linn.). J App Pharm Sci, 2018; 8(12):072-079. 